\title{
CURING SinUs HEADACHES AND TyING LAW: AN EMPIRICAL ANALYSIS OF BUNDLING DECONGESTANTS AND PAIN RELIEVERS
}

\author{
DAVID S. EVANS \\ MICHAEL A. SALINGER
}

CESIFO WORKING PAPER NO. 1519

CATEGORY 9: INDUSTRIAL ORGANISATION

August 2005

An electronic version of the paper may be downloaded

- from the SSRN website:

www.SSRN.com

- from the CESifo website: www.CESifo-group.de 


\title{
CURING SinUs HEADACHES AND TYING LAW: AN EMPIRICAL ANALYSIS OF BUNDLING DECONGESTANTS AND PAIN RELIEVERS
}

\begin{abstract}
We apply and extend the cost-based approach to bundling and tying under competition developed in Evans and Salinger (2004) to over-the-counter pain relievers and cold medicines. We document that consumers pay much less for tablets with multiple ingredients than they would if they bought tablets with each ingredient separately. We then decompose the sources of these savings into marginal cost savings and a component that reflects fixed costs of product offerings. The analysis both documents substantial economies of bundling and illustrates the sort of cost analysis that is necessary for understanding tying.
\end{abstract}

JEL Code: L11.

\author{
David S. Evans \\ LECG, Suite 300 \\ 350 Massachusetts Avenue \\ Cambridge, MA 02139 \\ USA \\ david_evans@lecg.com
}

\author{
Michael A. Salinger \\ Bureau of Economics \\ U.S. Federal Trade Commission \\ 600 Pennsylvania Ave., NW \\ Washington, DC 20580 \\ USA \\ msalinger@ftc.gov
}

This paper is a revision of "An Empirical Anlysis of Bundling and Tying: Over-the-Counter Pain Relief and Cold Medicines," which was prepared for CESifo Summer Institute 2004 Meeting on "Recent Trends In Antitrust," Venice, Italy, July 21-22, 2004, and circulated as CESifo working paper no. 1297.

Evans is Managing Director, Global Competition Policy, LECG, LLC and Visiting Professor, Faculty of Laws, University College London. Salinger is Director, Bureau of Economics, U.S. Federal Trade Commission and Professor of Economics, Boston University School of Management. Work on this paper was completed prior to his appointment at the FTC. The opinions expressed herein are those of the authors alone. This paper does not necessarily represent the position of the Federal Trade Commission, any of the individual commissioners, or any other organization. The authors thank Irina Danilkina, Chris Nosko, Sannu Shrestha and Ori Stitelman for exceptional research support and Tim Bresnahan, Howard Chang, Georg Getz, Anne Layne-Farrar, Nick Nichols, Bernard Reddy and Richard Schmalensee for comments and suggestions. Microsoft Corporation provided research funding for which the authors are grateful 


\title{
Curing Sinus Headaches and Tying Law: An Empirical Analysis of Bundling Decongestants and Pain Relievers
}

\author{
David S. Evans \\ Michael Salinger
}

May 2005

\section{Introduction}

At virtually any pharmacy, grocery store, or convenience store, one can purchase "cold tablets" that contain more than one active ingredient. The main components of these medicines are pain relievers, decongestants, antihistamines, and cough suppressants. Tablets (or other dosage forms) containing just one of the ingredients are also available. The tablets that contain more than one active ingredient are therefore examples of bundled products. ${ }^{1}$ This chapter reports an empirical analysis of the effects of this bundling.

Bundling and the related practice of tying have been central to several highprofile antitrust cases around the turn of the $21^{\text {st }}$ century in both the United States and Europe. ${ }^{2}$ The broad policy issue raised by these cases is how to distinguish

\footnotetext{
${ }^{1}$ A bundled product is one that combines more than one product that could be sold separately.

${ }^{2}$ U.S. v. Microsoft and New York, et al. v. Microsoft, Civil Action Nos. 98-1232 and 98-1233 (TPJ), July 17, 1998; In re Visa Check/MasterMoney Antitrust Litig., No. 96-CV-5238, 2003 U.S. Dist. LEXIS 4965, at 6 (E.D.N.Y. Apr. 1, 2003); Commission Decision of 24.03.2004 (Case COMP/C-3/37.792 - Microsoft), available at http://europa.eu.int/comm/competition/antitrust/cases/decisions/37792/en.pdf (accessed April 25, 2005); Apple is facing a host of antitrust lawsuits in Europe and the United States over its alleged tying of iPod and the iTunes music store. In November 2004, Conseil de la Concurrence, the French competition authority, dismissed a suit brought by Virgin against Apple asking the French government to compel Apple to license Fairplay, its DRM technology. See, Apple Conseil de la Concurrence, Décision n ${ }^{\circ}$ 04-D54 relative à des pratiques mises en oeuvre par la société Apple Computer, Inc. dans les secteurs du téléchargement de musique sur Internet et des baladeurs numériques, 9 November 2004. In 2005, a French consumer group launched another lawsuit against Apple and Sony's proprietary music formats, claiming that the respective digital rights management used by both companies, which prevent songs bought from their online music stores from being played on other manufacturers' media players is limiting consumers' choice. See Jo Best, “Apple, Sony sued over DRM in France," Silicon.com, February 14, 2005 , http://news.zdnet.com/2100-9588 22-5575417.html (accessed April 25, 2005). Apple is also facing a similar antitrust lawsuit in the United States. See Peter Cohen , "iTunes user sues Apple over FairPlay DRM,” MacCentral, January 26, 2005, http://www.macworld.com/news/2005/01/06/slattery/index.php
} 
Preliminary - Do not redistribute or cite without permission

anticompetitive cases of bundling and tying from the bundling and tying that occurs commonly under competition, presumably because it is efficient. Making that distinction requires a better understanding of bundling and tying under competition than the existing literature provides. This chapter is part of a project to advance our understanding of bundling and tying under competition both theoretically and empirically.

The remainder of this chapter is organized as follows. The following two sections provide background for our analysis. In section II, we discuss the antitrust treatment of bundling and tying, which is the policy issue that motivates our analysis. Section III briefly describes what we view as the principle shortcomings of the existing economics literature on bundling and tying and offers a new framework that we propose in order to address those shortcomings.

Sections IV-VI then present our analysis of the bundling of cold medicines and pain relievers. Section IV describes the data and establishes three main empirical regularities. First, the discounts for buying bundled products are substantial. Second, so are the discounts for buying products in larger package sizes. Third, some products come in different dosages. For example, acetaminophen is sold as regular strength (325 milligrams), extra strength (500 milligrams), and arthritis strength (650 milligrams). Holding package size constant, the cost per unit of active ingredient is lower for higher dosages. Qualitatively, none of these results is surprising; our contribution lies in quantifying them.

Section V shows how to apply the framework described in Section III to the bundle discount. Under that theory, a bundle discount can be the result of two distinct

(accessed April 25, 2005). Also see, Kinetic Concepts, Inc. v. Hillenbrand Indus., 262 F. Supp. 2 d 722 (W.D. Tex. 2003). 
Preliminary - Do not redistribute or cite without permission

cost effects. One is marginal cost savings (that could arise, for example, from conserving on the number of packages and tablets produced). The other is a reduction in the contribution to fixed costs of each product offering (such as the cost of a shelf slot or the system cost of an additional stock keeping unit). As we will explain, ${ }^{3}$ whether the private savings consumers get from the bundle reflect social savings as well depends on the relative contribution of each. Thus, to estimate cost savings from bundling, we must empirically identify these two effects.

The key empirical contributions in the paper are presented in Section VI, which we summarize in some detail here to motivate the analysis. We exploit the regularities in the pricing of different package sizes to identify the marginal cost savings and fixed cost increase effects. Some economists might argue that this pricing should be viewed as an optimal quantity-dependent pricing scheme. We suggest the alternative hypothesis that it reflects the same cost factors that give rise to discounts for bundled products. Suppose, for example, that a particular medicine - acetaminophen - is available in packages of 50, 100 , and 200 tablets, with the price per tablet a decreasing function of tablet size. There seems to be no reason to rule out the possibility that some customers would ideally like to purchase 150 tablets. Such a customer could either buy one package of 100 tablets and one of 50 tablets, thus sacrificing potential economies of package size, or one package of 200 tablets that contains 50 more tablets than he wants. We estimate how high fixed costs would have to be to make it unprofitable to offer package sizes that we do not observe. As a basis for these estimates, we extend the model discussed in Section III to packagesize effects.

\footnotetext{
${ }^{3}$ See Section III.
} 
Preliminary - Do not redistribute or cite without permission

We estimate that, in this case, the marginal cost savings from bundled products exceed the fixed costs of the product offerings, so bundling lowers costs. For example, we estimate that the price of a package of 48 tablets that combines two active ingredients is $\$ 3.60$ less $^{4}$ than the sum of the prices of the same ingredients sold in separate packages of 48 tablets each. We decompose this $\$ 3.60$ into a marginal cost increment of $\$ 2.40$ and an average fixed cost of $\$ 1.20$. The net cost effect is the difference between the two, or $\$ 1.20$. The gain would be substantially larger for tablets that contain three active ingredients. Moreover, these cost effects do not capture the value of the convenience consumers get from bundled products.

We can also use our framework to estimate the cost savings from having the separate products available rather than having consumers who want just one component buy the bundled product. This type of calculation is important for addressing the policy issues associated with the antitrust laws concerning tying. Tying occurs when a bundled product is offered and at least one of the separate products is not. Since tying can be an antitrust violation, the law encourages companies, at least those with market power, to offer the products that it bundles as separate goods as well. For a consumer who wants just one component of a bundle, buying the separate component rather than the bundle saves the marginal cost of the components he does not want. However, the separate component is itself a distinct product that generates a fixed cost of offering it. Selling the separate component only saves costs if the fixed cost is less than marginal costs avoided by not providing a customer with the part of a bundle he does not want.

\footnotetext{
${ }^{4}$ The percentage difference would vary with the active ingredients but would generally be between 30 percent and 50 percent.
} 
Preliminary - Do not redistribute or cite without permission

While in most of the cases we consider our estimates indicate that the separate products save costs, there is one case in which we estimate that it does not. Of course, this result does not imply that the separate product should not be offered. In the example we consider, consumers who want, for example, just pain relief, would strictly prefer not to have to take a decongestant at the same time. Just as a complete welfare analysis of bundling and tying would have to account for the convenience value of the bundle for consumers who want all the components, so would it also have to account for the possibility that some consumers would pay not to have a component of a bundle.

The concluding section argues that the approach we have developed in this chapter can and should be used more generally to examine the economics of bundling specifically, and possible efficiency explanations for various business practices that are often found suspect under the antitrust laws.

\section{Policy Background}

The policy issue that motivates our analysis is the antitrust treatment of bundling and tying. Bundling is the practice of selling in combination two or more goods that could be sold separately. Tying occurs when a firm sells a bundled product but does not sell one of the components individually. "Mixed bundling" arises when a firm sells all the components separately but offers a discount for the bundled product. In principle, it is tying rather than bundling that has historically raised antitrust concerns. ${ }^{5}$ However, a

\footnotetext{
${ }^{5}$ See Philip Areeda and Herbert J. Hovenkamp, Antitrust Law: An Analysis of Antitrust Principles and Their Application (Boston, MA: Little, Brown and Co., 1978).
} 
Preliminary - Do not redistribute or cite without permission

sufficiently large bundle discount is sometimes interpreted as a virtual tie, and mixed bundling has emerged as an issue in its own right in Europe. ${ }^{6}$

Courts in the European Community and in the United States have found that tying should be treated with almost as little doubt as price fixing. In both cases the courts have decided that the offense is unlawful per se. That is, the courts do not need to inquire much, if at all, into the competitive effects of the practice or give much weight to procompetitive justifications. In the United States, tying is the only unilateral practice for which the courts have not incorporated microeconomic reasoning, following in the tradition established by certain economists and legal schools associated with the University Chicago. ${ }^{7}$

\footnotetext{
${ }^{6}$ See John Kallaugher and Brian Sher, "Rebates Revisited: Anti-Competitive Effects and Exclusionary Abuse Under Article 82," European Competition Law Review 25(5) (2004): 263-285; Hans-Georg Kamann and Ellen Bergmann, "The Granting of Rebates by Market Dominant Undertakings under Article 82 of the EC Treaty," European Competition Law Review 26(2) (2005): 83-89.

${ }^{7}$ See David S. Evans and A. Jorge Padilla, "Designing Antitrust Rules for Assessing Unilateral Practices: A Neo-Chicago Approach," University of Chicago Law Review (Forthcoming, 2005).
} 
Preliminary - Do not redistribute or cite without permission

\section{A. European Community Tying Law}

In the European Community, Hilti is one of the two leading cases on tying (the other being Tetra Pak II). ${ }^{8}$ Hilti made nail guns used for construction work. The nail guns at the time of the case used separate cartridges and nails. Hilti had patents on the cartridges for use in its guns. It required customers buying its cartridges to also buy its nails. Cartridges and nails are obviously used in fixed proportions. The European Court of Justice, affirming a decision by the Court of First Instance, agreed that this was an unlawful tie because Hilti was dominant in cartridges and cartridges and nails were separate products.

Economists recognize this case as a straightforward application of the Chicago single-monopoly profit theorem. ${ }^{9}$ With fixed proportions there is only one possible monopoly profit. Hilti can earn all of its monopoly profits from the cartridges and is therefore indifferent, on this basis at least, on whether it sells the nail at a competitive price or someone else does. Price discrimination and metering for the intensity of use of the nail gun cannot explain the practice either since the cartridges suffice for that. Thus, Hilti's explanation that there were safety issues seems more persuasive than a monopolization story.

\footnotetext{
${ }^{8}$ Case C-53/92P Hilti AG v. Commission [1994] ECRI-667; Case T-5/02, Tetra Laval v. Commission, 2002 E.C.R. II-4382.

${ }^{9}$ Aaron Director and Edward H Levi, "Law and the Future: Trade Regulation," Northwestern University Law Review 51 (May-June 1956): 281-96. Also see, Jean Tirole, The Theory Of Industrial Organization (Cambridge, MA: The MIT Press, 1988).
} 
Preliminary - Do not redistribute or cite without permission

\section{B. U.S. Tying Law}

In the United States, tying law is based on the Supreme Court's decision in Jefferson Parish. ${ }^{10}$ A hospital had an exclusive contract with a group of anesthesiologists and required surgical patients to use one of those anesthesiologists. A competing anesthesiologist claimed this was an unlawful tie. The Supreme Court enunciated a new test for tying that was somewhat more forgiving than the earlier ones. A tie was unlawful if there were two separate products, a firm with market power in one product required customers to take the other product, and this requirement affects a not-insubstantial amount of interstate commerce. Two products were separate if there was enough consumer demand for the tied product to offer it separately.

The Supreme Court agreed with the appeals court that surgical and anesthesiology services were separate products. The record showed that many anesthesiologists were not employed by hospitals; patients--women having babies for example-- sometimes hire their own anesthesiologists. The appeals court had rejected a number of arguments presented by the hospital that there were efficiencies from having an exclusive contract with a group of anesthesiologists. The Supreme Court nevertheless found that the tie was not unlawful because Jefferson Parish did not have market power. That leads one to question the power of the test: if the tie was not efficient, and if Jefferson Parish did not have market power to secure an extra monopoly profit, why did it engage in the tie in the first place?

The situation is not quite as extreme in practice as it appears on paper. Tying, unlike price fixing, is common and conducted by many companies quite openly. MIT Press, for example, will not sell you this chapter without you also taking Tim 
Preliminary - Do not redistribute or cite without permission

Bresnahan's. Competition authorities ignore many cases they could prosecute. And the courts in the United States often find reasons to define tying away. ${ }^{11}$ But companies that get caught up in tying cases find that these cases lead to significant changes in their businesses.

In March 2004, the European Commission found that Microsoft had engaged in an unlawful tie by distributing Windows with media player technologies included without also offering Windows with media player technologies excluded. ${ }^{12}$ To remedy this violation the Commission required Microsoft to distribute a version of Windows with 182 media player related files deleted (although it has allowed Microsoft to distribute this at the same price as the complete version since media players are generally available for free). ${ }^{13}$

Microsoft also faced a claim brought by the U.S. Department of Justice that it tied its operating system to its browser. ${ }^{14}$ A district court found that was illegal under the Jefferson Parish test. An appeals court created a "software platform" exception to the standard per se test and remanded the case to be considered under the "rule of reason."15 The Justice Department decided not to retry the charge. ${ }^{16}$

Microsoft is not the only company to face tying claims. In April 2003, MasterCard and Visa settled a class-action case for \$3 billion in cash and more in

\footnotetext{
${ }^{10}$ Jefferson Parish Hosp. Dist. No. 2 v. Hyde, 104 S. Ct. 1551 (1984).

${ }^{11}$ Compuware Corp. v. IBM, 259 F. Supp. 2d 597 ( E.D. Mich., 2003).

${ }^{12}$ Commission Decision of 24.03.2004 (Case COMP/C-3/37.792 - Microsoft), at $\uparrow \uparrow ~ 792-993$.

${ }^{13}$ Id., at $\uparrow \uparrow 1011-23$.

${ }^{14}$ U.S. v. Microsoft and New York, et al. v. Microsoft, Civil Action Nos. 98-1232 and 98-1233 (TPJ), July $17,1998$.

${ }^{15}$ U.S. v. Microsoft, 253 F.3d 34 (D.C. Cir. 2001), at 158.

${ }^{16}$ The appeals court in another part of the decision found that the government had failed to prove the existence of a browser market and precluded it from retrying that portion of the case. That made it especially difficult for the Justice Department to proceed under a rule of reason analysis since it needed to demonstrate harm in the browser market.
} 
Preliminary - Do not redistribute or cite without permission

concessions after a district court judge found, on summary judgment and before a jury trial on the facts, that the card associations had passed most, and possibly all, of the tests necessary for finding an unlawful tie. ${ }^{17}$ The card association required merchants that accepted their credit cards to also take their debit cards (as part of a general rule known as the "honor-all-card rule"). As part of the settlement, the card associations agreed to let merchants take credit cards without also taking debit cards. American Express is facing a similar class-action lawsuit because it "ties" merchants' acceptance of its corporate card to the acceptance of its non-corporate cards. ${ }^{18}$

\section{Bundling}

Although it is not the focus of the analysis below, it should be mentioned that another strand of antitrust law in the European Community and the United States finds that what we have called mixed bundling can be anticompetitive. The issue hinges on pricing. At the simplest level, a company can offer choices but set the prices in such a way that it is equivalent to tying. The more interesting case, though, involves setting prices for the various bundles in ways that arguably foreclose competitors from competing in certain product markets. The Court of First Instance found in several cases that "fidelity discounts"- discounts that in effect encouraged firms to buy multiple products from a single firm—violated Article 82 EC Treaty. ${ }^{19}$

\footnotetext{
${ }^{17}$ In re Visa Check/MasterMoney Antitrust Litig., No. 96-CV-5238, 2003 U.S. Dist. LEXIS 4965, at 6 (E.D.N.Y. Apr. 1, 2003); Jennifer Bayot, "Final Pact Approved in Long-Running Debit Card Litigation," New York Times, December 20, 2003.

${ }^{18}$ Merchant class action suit against American Express, Citigroup, and MBNA (New York, 2003); "Stop Me if You've Heard This One: Merchants Sue Card Company," The Green Sheet, Inc., February 01, 2005, http://www.greensheet.com/PriorIssues-/050201-/7.htm (accessed April 25, 2005) .

19 These included buying different types of tires (Case T-203/01, Manufacture française des pneumatiques Michelin v. Commision, Sept 30, 2003) and providing discounts to travel agents who used a particular airline (Case T-219/99, British Airways plc v. Commission, Dec. 7, 2003). Coca Cola settled a related case
} 
Preliminary - Do not redistribute or cite without permission

In the United States, in a controversial decision, the Third Circuit Court of Appeals affirmed a jury verdict that found that $3 \mathrm{M}$ had violated the Sherman Act by providing discounts for purchasing several $3 \mathrm{M}$ products. It did so apparently in the absence of any evidence that any of the individual prices were below marginal cost. ${ }^{20}$

\section{Economics Literature on Tying and Bundling}

In this section, we briefly comment on the existing economics literature on bundling and tying and then describe the alternative framework we have developed for understanding bundling and tying under competition.

\section{A. Existing Literature}

The economics literature on bundling and tying has largely been a normative one motivated by the antitrust issues. The early legal hostility toward tying was based on informal notions that the practice could be used to leverage monopoly in one market into some other market. George Stigler presented an alternative interpretation that gave rise to the price discrimination strand of the literature. Then, starting with Whinston (1990), the literature has revisited the foreclosure theory using game theory as an analytic tool. We now understand that one can construct a formal economic model in which tying is used to exclude competitors.

with the European Commission by agreeing to eliminate various bundled discounts. Commission Decision of 10/19/2004 (CASE COMP/39.116/B-2 - COCA-COLA).

${ }^{20}$ See Daniel L. Rubinfeld, “3M's Bundling Rebates: An Economic Perspective," Chicago Law Review 72 (2005): 243-264. 
Preliminary - Do not redistribute or cite without permission

Ironically, even though the intent of the literature has been to provide insight into antitrust policy, it has simply failed to address the most important issue policy makers need to confront. Both tying and mixed bundling are common practices under competition. The challenge for antitrust policy is to distinguish anticompetitive tying and bundling from the tying and bundling that commonly occurs under competition and is therefore presumed to be efficient. The literature suffers from three major shortcomings that prevent it from achieving this task. First, it is based on the assumption that firms have market power. Second, it is based on the assumption that bundling and tying do not create efficiencies of any type, which is why bundling and tying occur under competition. Even at a theoretical level, one cannot distinguish between competitive tying and anticompetitive tying by understanding anticompetitive tying alone. One needs to understand competitive tying as well to know the difference. The third shortcoming of the literature is that it is almost entirely theoretical.

The lack of empirical content is problematic for two distinct reasons. First, courts cannot be expected to distinguish perfectly between competitive and anticompetitive examples of bundling and tying. In light of the risk of error, the relative frequency of competitive and anticompetitive tying and bundling and the costs of "false convictions" and "false acquittals" are relevant considerations in formulating legal standards. ${ }^{21}$ For the foreseeable future, notions of the relative frequencies will have to be subjective; ${ }^{22}$ but careful observation of bundling and tying in practice would seem to be helpful and indeed essential in judging the probabilities. Secondly, the economics literature has not

\footnotetext{
${ }^{21}$ See Keith N. Hylton and Michael A. Salinger, "Tying Law and Policy: A Decision Theoretic Approach," Antitrust Law Journal 69 (2001): 469.
} 
Preliminary - Do not redistribute or cite without permission

developed the analytical framework to do the cost-benefit analysis of actual cases in which tying and bundling help some customers but harm others.

\section{B. A New Framework}

In Evans and Salinger (2004, 2005), we present a new model of bundling and tying designed to address the shortcomings of the existing literature. First, we examine these practices under competition and thereby provide a basis for comparing competitive and anticompetitive theories of these practices. Second, while further development is needed, we believe that our framework has the potential to be more tractable for empirical analysis than existing models. Indeed, the empirical analysis we present in this paper represents the first attempt to implement the model empirically.

To understand tying under competition, one must first recognize that consumers differ in their preferences for what they want. Businesses cannot necessarily customize their offerings to provide each customer exactly what he wants. A simple framework that captures this basic idea goes as follows. There are two goods, A and B, which can be sold separately or in combination. Some customers want just good A, some want just good B, and some want both. Those who want both might strictly prefer to buy them in bundled form. This could be because the bundling provides convenience, in which case they would be willing to pay a premium to buy the bundle rather than to buy the components separately. Alternatively, bundling might save marginal costs, which, under competition, get passed on to consumers through lower prices.

\footnotetext{
${ }^{22}$ See Warren S. Grimes, "The Antitrust Tying Law Schism: A Critique of Microsoft III and A Response to Hylton and Salinger," Antitrust Law Journal 70 (2002): 199-230; Keith N. Hylton and Michael A. Salinger, "Tying Law and Policy: A Decision Theoretic Approach,” Antitrust Law Journal 69 (2001): 469.
} 
Preliminary - Do not redistribute or cite without permission

Given this general set-up, mixed bundling gives each group of customers the exact product its "members" want. Assuming that there are at least some people in each of the three demand groups, anything other than mixed bundling represents a limitation on the set of products that are offered. If the bundle is the "good" not offered, then no tying occurs. If, however, the bundle is offered and one or both components are not, then the result is tying.

As is generally recognized in the economics literature on product selection, companies cannot customize their offerings to the preferences of each customer because of scale economies associated with each product offering. To be offered, therefore, the presence of some demand for a good is not sufficient. There must be a critical mass of customers. The simplest way to capture these scale economies is to assume a fixed cost associated with each product offering, where each component and the bundled product are separate offerings.

The assumption of a fixed cost of a product offering poses a dilemma for modeling tying under competition. Under perfect competition, price equals marginal cost. With a fixed cost associated with each product offering, however, marginal cost is less than average cost, marginal cost pricing would not allow a firm to cover its cost. Rather than assuming perfect competition, therefore, we assume that markets are perfectly contestable in the sense of Baumol, Panzer, and Willig (1982). We then model the set of products offered by looking for "sustainable prices."

To take an example, consider pure bundling, which means that the bundle is offered but neither component is. When that happens, customers who want just good A or just good B have to buy the bundle and discard the good they do not want. Under the 
Preliminary - Do not redistribute or cite without permission

contestability assumption, the price of the bundle equals its average cost, which is the sum of the marginal cost and the fixed cost averaged over all the customers who buy it. For pure bundling to be sustainable, then it must not be possible to offer, say, just good A at a price below the price of the bundle under pure bundling. If the marginal cost of good A is less than the marginal cost of the bundle, as would typically be the case, then pure bundling would not be sustainable given sufficiently large demand for good A. If, however, demand for just good A is sufficiently limited, then the marginal cost savings from providing good A alone might be less than the fixed cost of the separate product offering. If so, and if the same is true for $\operatorname{good} \mathrm{B}$, then pure bundling can be sustainable.

Simple as the framework is, it leads to powerful insights. In particular, pure bundling can occur under two distinct types of circumstances. One is that most customers want both goods, there are marginal cost savings from offering them together, and demand for the separate goods, while present, is too small to justify offering them. A commonly cited but trivial example is shoes - few people want their shoes without laces and few want only one shoe; but few does not mean none since surely some people have their favorite laces and there are at least a few amputees and people in casts who only want one shoe. Men's and women's suits are an interesting example. In the United States, tailoring is usually tied in for men, so men who have their own favorite tailor are perhaps disadvantaged; tailoring is usually not tied for women who sometimes complain that this is discriminatory.

The other condition that gives rise to pure bundling in this model is that fixed costs are very high. In this case, pure bundling can arise even if no one wants both components. If so, everyone in effect purchases an unwanted component. Yet, the high 
Preliminary - Do not redistribute or cite without permission

fixed cost makes it efficient to provide a standardized product that meets the needs of a diverse group of customer wants. For example, some computer software is sold in boxes that contain both a Macintosh and PC version. It is likely that very few people want both. Many college textbooks contain more material than can be covered in a single course so that they can be useful for professors with diverse preferences about what material they want their students to read.

We now turn to our empirical application of this framework.

\section{The Pricing of Pain Relief, Cold, Sinus, and Allergy Medicines}

The primary data collected for this paper were the prices of all cold ${ }^{23}$ and pain relief medications sold at the Walgreens ${ }^{24}$ at 757 N. Michigan Ave. in Chicago on April 3, 2003. For each package, we observe the brand, the price, dosage form, ${ }^{25}$ quantity of each active ingredient per unit, and number of units. We have supplemented the data with some prices offered at the website of $\mathrm{CVS}^{26}$ and have generally checked prices on the web and at other outlets to confirm that the regularities we document are not specific to this particular location and time.

\section{A. Empirical Regularities}

\footnotetext{
${ }^{23}$ We use the term "cold" to include medications labeled as sinus, allergy, and cough as well.

${ }^{24}$ Walgreens is the largest pharmacy chain in the United States. It has a 20 percent share of retail pharmaceuticals sales. CVS is the second largest pharmacy chain with a 16 percent share. Source: "CVS Is Good Medicine For Investors," Dow Jones News Service, February 25, 2004.

${ }^{25}$ Dosage forms include tablets, caplets, liquid, "gel tabs," etc.

${ }^{26}$ The website www.cvs.com is a vehicle for ordering pharamaceuticals (and other products) to be delivered by mail. The website is operated by CVS, which also operates a large chain of retail pharmacies.
} 
Preliminary - Do not redistribute or cite without permission

We will ultimately use a price regression to describe the bundle discount. To guide the specification of that regression, it will be useful to explore less formally some strong regularities that are present in the data. We will use these stylized facts to argue for a cost-based explanation for the bundle discount.

\section{Bundle Discounts and Brand Name Premia}

Johnson \& Johnson's Tylenol is the dominant brand of the pain reliever acetaminophen and Pfizer's Sudafed is the dominant brand of the decongestant pseudoephedrine hydrochloride. Each Extra Strength Tylenol contains $500 \mathrm{mg}$ of acetaminophen and each Maximum Strength Sudafed contains $30 \mathrm{mg}$ of pseudoephedrine hydrochoride. Johnson \& Johnson does not offer a Tylenol-brand pseudoephedrine hydrochloride nor does Pfizer offer a Sudafed-brand acetaminophen. However, both a Tylenol Sinus Caplet and a Sudafed Sinus and Headache Caplet contain $30 \mathrm{mg}$ of pseudoephedrine hydrochloride and $500 \mathrm{mg}$ of acetaminophen. ${ }^{27}$ Table 3.1 lists the prices we observed for 24-tablet packages of these products and for their store-brand equivalents. ${ }^{28}$ Table 4.1 illustrates two general phenomena in the pricing of this class of product. First, branded products command a substantial premium over the price of the CVS product - from around 30 percent to 50 percent. Second, within both the branded and non-branded segments, the price of the combination product is much lower than the sum of the prices of the stand-alone products. The incremental cost to a consumer of the

\footnotetext{
${ }^{27}$ Novartis also offers a product that contains $500 \mathrm{mg}$ of acetaminophen and $30 \mathrm{mg}$ of pseudoephedrine hydrochloride, Tavist Allery/Sinus/Headache.

${ }^{28}$ These data are taken from www.cvs.com rather than our Walgreens data set. To isolate the bundle discount, we need to hold package size constant. To do so, we need all six of the products in Table 4.1 (just acetaminophen, just pseudophedrine, and the combination tablet in branded and generic form) available in a common package size. Our Walgreens data set did not generate such a comparison, but the data we obained from the CVS website did.
} 
Preliminary - Do not redistribute or cite without permission

pseudoephedrine hydrochloride in the Tylenol Sinus Caplet over purchasing just Extra

Strength Tylenol is $\$ 2.00$, which is only 44 percent of the price of buying a package of 24

Sudafed tablets. The incremental price of the acetaminophen in the Sudafed Sinus and

Headache Caplets is $\$ 1.40$, which is 35 percent of the price of buying a package of 24

Extra Strength Tylenol tablets. The comparisons are even more striking with the CVS

products. The incremental price of the acetaminophen in the combination product over pseudoephedrine hydrochloride tablets is only $\$ 0.50$, or 17 percent of the price of buying acetaminophen tablets separately. ${ }^{29}$

Table 4.1. Prices for 24 Tablet/Caplet Packages

\begin{tabular}{|c|c|c|c|}
\hline Brand & Combination & Pseudoephedrine HCl Alone & Acetaminophen Alone \\
\hline Tylenol & $\$ 5.99$ & NA & $\$ 3.99$ \\
\hline Sudafed & $\$ 5.99$ & $\$ 4.59$ & NA \\
\hline CVS & $\$ 3.99$ & $\$ 3.49$ & $\$ 2.99$ \\
\hline
\end{tabular}

Note: Tylenol: "Tylenol Sinus Caplet" (the combination product) and "Tylenol Extra Strength Caplets." Sudafed: "Sudafed Sinus and Headache Caplet" (the combination product) and "Sudafed Sinus \& Cold." CVS: "Non-Aspirin Sinus Caplets Maximum Strength" (the combination product), "Nasal Decongestant Tablets Maximum Strength," and "Non-Aspirin Caplets Extra Strength." NA denotes a combination that was not offered. Doses are $30 \mathrm{mg}$ of pseudoephedrine hydrochloride and $500 \mathrm{mg}$ of acetaminophen.

Source: Downloaded from CVS website, http://www.cvs.com, February 11, 2004.

There are also products that combine pseudoephedrine hydrochloride and ibuprofen.

Here, the comparisons are not quite as clean because we observed package sizes of 20 rather than 24 for the combination product. Still, as we will document in section II.A.3 below (and as is well known), the price per pill is generally a decreasing function of package size. Thus, comparing the price per pill of the bundled product with the sum of the prices per pill of the component products sold in somewhat larger packages understates the gains from bundling.

\footnotetext{
${ }^{29}$ In our Walgreens data set, the comparable prices were $\$ 6.99$ for 24 Tylenol Sinus tablets, $\$ 4.99$ for 24 Extra Tylenol tablets, and $\$ 6.79$ for 24 Sudafed tablets. Thus, the price of the branded combination product was only $\$ 0.20$ higher than the stand alone Sudafed product. For the Walgreens brands, the prices were \$2.99 for 24 tablets of extra strength acetaminophen and \$3.49 for 24 maximum strenght pseudoephedrine hydrochloride tablets. While we did not observe a Walgreens version that combined just these two active
} 
Preliminary - Do not redistribute or cite without permission

We observed a price of \$6.29 for a package of 20 Advil "Cold \& Sinus" tablets, which is less than $\$ 0.32 /$ tablet. To buy Advil and Maximum Strength Sudafed separately in 24-tablet packages, the sum of the prices per pill would be more than $\$ 0.49 /$ tablet. $^{30}$ On a per-pill basis, the price of the bundled product was 64 percent of the price of the components. For the store-brand versions, the per-pill price of the bundled product was less than $\$ 0.21$, which was 21 percent less than $\$ 0.27$, the sum of the per-pill prices of the two separate products. ${ }^{31}$

The strong stylized fact that emerges from this set of comparisons is that the prices consumers pay for combinations of medicines — both branded and store-brand - are substantially less than the prices they would pay to buy the same active ingredients as separate medicines. Of course, consumers who want all the components of the combination medicines likely get convenience as well as the lower price.

\section{Pricing of Different Dosages}

The phenomenon of lower prices for combining the same active ingredient into fewer pills and distinct packages that we observed with combination drugs applies to different doses of the same medicine.

\section{a) Pain Relievers}

Tylenol comes in three dosage forms for adults: ${ }^{32}$ Regular Strength (325 mg/tablet), Extra Strength (500 mg/tablet), and Arthritis Strength (650 mg/tablet). In a sense, each

\footnotetext{
ingredients, we did observe a package of 24 tablets with these two ingredients and 25 milligrams of the antihistimine, Diphenhydramine $\mathrm{HCl}$. The price was $\$ 3.99$.

${ }^{30}$ The price we observed for 24 Advil tablets was $\$ 4.99$. As reported in note 29 , we observed a price of $\$ 6.79$ at Walgreens for a package of 24 Sudafed tablets.

${ }^{31}$ The Walgreens products are WalProfem tablets (ibuprofen), WalPhed (pseudoephedrine hydrochloride) and WalProfem Cold \& Sinus. The prices we observed were $\$ 4.29$ for 20 WalProfem Cold \& Sinus tablets, $\$ 2.99$ for 24 WalProfem tablets, and $\$ 3.49$ for 24 WalPhed tablets.

${ }^{32}$ It also comes in junior and children's doses.
} 
Preliminary - Do not redistribute or cite without permission

Arthritis Strength tablet is a bundle of two Regular Strength tablets. As a result, buying two packages of, say, 100 Regular Strength Tylenol rather than one package of 100 Extra Strength Tylenol is analagous to buying Tylenol and Sudafed separately rather than in "sinus tablet" form.

Table 4.2 presents prices we observed that reveal the economies of combining products as well as the general pricing structure for Tylenol. First, note that in the two cases in which the number of tablets is held constant (50 and 100), the incremental price of the higher levels of extra ingredients is small. At the 50-tablet size, the arthritis strength contains 30 percent more active ingredient for an incremental price of only $\$ 0.20$, or 2.8 percent. At the 100-tablet size, the Arthritis Strength price is 10 percent higher than the Extra Strength price. In turn, Extra Strength contains approximately 50 percent more active ingredient than regular strength for an incremental price of $\$ 0.60$ or 6.4 percent. The comparison that most corresponds to the bundling comparison in the previous section is between purchasing one package of 100 Arthritis Strength tablets and two packages of 100 Regular Strength Tablets. The amount of active ingredient is the same, but buying two packages of Regular Strength entails two packages rather than one and twice as many tablets. As Table 4.2 indicates, the price of the one Arthritis Strength package is $\$ 10.99$ while the price of two Regular Strength packages is $\$ 18.78 .^{33}$

\footnotetext{
${ }^{33}$ Note further that a package of 60 Extra Strength Tylenol has about the same active ingredient as 100 Regular Strength and costs $\$ 1.50$ less.
} 
Preliminary - Do not redistribute or cite without permission

Table 4.2. Prices for Different Tylenol Dosages

\begin{tabular}{cccc}
\hline Number & $\begin{array}{c}\text { Regular Strength } \\
(325 \mathrm{mg})\end{array}$ & $\begin{array}{c}\text { Extra Strength } \\
(500 \mathrm{mg})\end{array}$ & $\begin{array}{c}\text { Arthritis Strength } \\
(650 \mathrm{mg})\end{array}$ \\
\hline 50 & & $\$ 7.19$ & $\$ 7.39$ \\
60 & & $\$ 7.89$ & \\
100 & $\$ 9.39$ & $\$ 9.99$ & $\$ 10.99$ \\
150 & & $\$ 14.29$ & \\
\hline
\end{tabular}

Source: Prices observed at Walgreens at 757 N. Michigan Ave. in Chicago on April 3, 2003.

Table 4.3 shows similar data for Walgreens' acetaminophen. Here, the evidence is more mixed. The clean comparison that is comparable to the cold medicines is the 100tablet size. The total price of two packages of Regular Strength acetaminophen is $\$ 9.98$, which is about 25 percent more than the $\$ 7.99$ price of a single package of Arthritis Strength. However, it is not universally true that the per-milligram price of the arthritis strength is lower than the per-milligram price of the others. ${ }^{34}$

Table 4.3. Prices for Different Walgreens Acetaminophen Dosages and Package Sizes

\begin{tabular}{cccc}
\hline Number & $\begin{array}{c}\text { Regular Strength } \\
(325 \mathrm{mg})\end{array}$ & $\begin{array}{c}\text { Extra Strength } \\
(500 \mathrm{mg})\end{array}$ & $\begin{array}{c}\text { Arthritis Strength } \\
(650 \mathrm{mg})\end{array}$ \\
\hline 24 & & $\$ 2.99$ & $\$ 3.99$ \\
50 & & & $\$ 5.49$ \\
60 & $\$ 4.99$ & $\$ 3.99$ & \\
100 & & $\$ 5.99$ & $\$ 7.99$ \\
175 & & $\$ 7.99$ & \\
250 & & $\$ 8.99$ & $\$ 13.99$ \\
500 & & $\$ 11.99$ & \\
\hline
\end{tabular}

Source: Prices observed at Walgreens at 757 N. Michigan Ave. in Chicago on April 3, 2003.

\footnotetext{
${ }^{34}$ All but one of the prices in Table 4.3 are $\$ 0.01$ less than an even dollar, with the other being $\$ 0.01$ less than an integral multiple of $\$ 0.50$. This feature of the pricing could be part of the explanation for why the price of Arthritis Strength does not show evidence of bundling efficiencies. For example, a price of $\$ 3.49$ for the package of 24 might not be sufficient to cover the incremental cost. Also, as we will discuss further below, if demand for this package size of Arthritis Strength is sufficiently low, then a higher margin might be needed to cover the fixed cost of the shelf space.
} 
Preliminary - Do not redistribute or cite without permission

\section{b) Decongestants}

Pseudoephedrine hydrochloride comes in three dosage forms. "Maximum Strength" contains $30 \mathrm{mg}$ per tablet. The "12-hour version" contains $120 \mathrm{mg}$ per tablet and the "24-hour version" contains $240 \mathrm{mg}$ per tablet. Table 3.4 lists the prices that we observed for different package sizes and dosage forms of Sudafed, Contac (another brand of pseudoephedrine hydrochloride) and Walgreens pseudoephedrine hydrochloride. Table 4.4 provides one clean comparison that is analogous to the bundling analysis above. The price of one package of ten 24-hour Sudafed tablets is $\$ 9.99$, whereas the sum of the prices of two packages of ten 12-hour Sudafed tablets is $\$ 12.98$. Note further that the price of five 24-hour Sudafed tablets is somewhat less than the price of ten 12-hour tablets and that the price of ten 24-hour Sudafed tablets is somewhat less than the price of twenty 12-hour tablets. The differences are not large. However, the obvious source of cost savings from the 24-hour version concerns placing the medicine into tablets. Since the absolute difference in the number of tablets is small, one would not expect large cost differences. $^{35}$

Table 4.4. Prices for Different Brands, Dosages and Package Sizes of Pseudoephedrine Hydrochloride

\begin{tabular}{ccccccc}
\hline & \multicolumn{2}{c}{$30 \mathrm{mg} /$ tablet } & \multicolumn{3}{c}{$120 \mathrm{mg} /$ tablet } & \\
Number of Tablets & Sudafed & Walgreens & Contac & Sudafed & Walgreens & $\begin{array}{c}\text { Sudafed } \\
\text { Sublet }\end{array}$ \\
\hline 5 & & & & & & $\$ 5.99$ \\
10 & & & $\$ 6.79$ & $\$ 6.49$ & $\$ 3.99$ & $\$ 9.99$ \\
20 & & & $\$ 9.49$ & $\$ 10.49$ & $\$ 6.49$ & \\
24 & $\$ 6.79$ & $\$ 3.49$ & & & & \\
48 & $\$ 9.49$ & $\$ 5.99$ & & & & \\
96 & & $\$ 14.99$ & & & & \\
\hline
\end{tabular}

Source: Prices observed at Walgreens at 757 N. Michigan Ave. in Chicago on April 3, 2003.

\footnotetext{
${ }^{35}$ Note that one odd feature of the table is that the price of 96 Walgreens Maximum Strength tablets is more than double the price of a package with half the number of tablets. That price is the exception, however. In general, the price per tablet is lower for larger package sizes.
} 
Preliminary - Do not redistribute or cite without permission

\section{Package Size Effects}

The third empirical regularity we document concerns package size, which is another form of bundling. A package of 200 tablets is a bundle of two packages of 100 tablets. In addition to providing evidence of another source of gains from bundling, evidence on the prices of different package sizes will yield insights into the fixed costs of product offerings.

Pain relief medications provide better evidence about package size effects than do decongestants or antihistamines because they come in a broader range of package sizes. Figure 4.1 presents the data on extra strength acetaminophen and Figure 4.2 presents the data on ibuprofen. Each graph contains two series, one for branded versions and one for the Walgreens product. All four of the series are concave and would appear to have a positive intercept.

Figure 4.1. Extra Strength Acetaminophen Prices

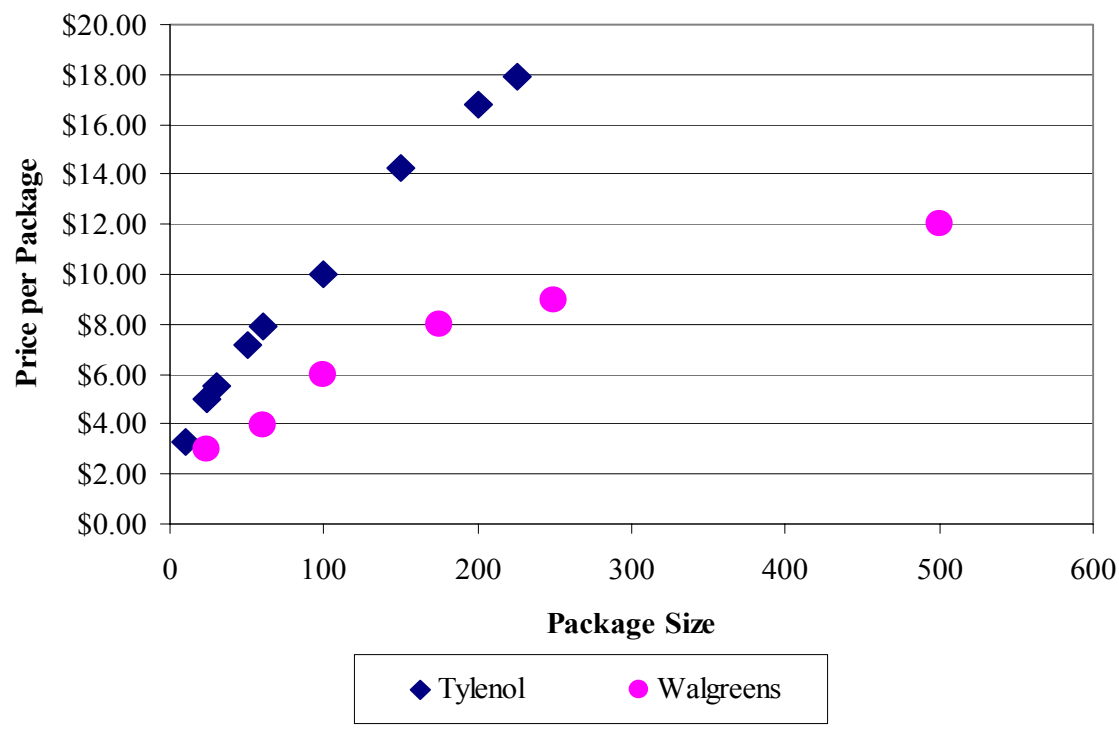


Preliminary - Do not redistribute or cite without permission

Figure 4.2. Extra Strength Acetaminophen Prices

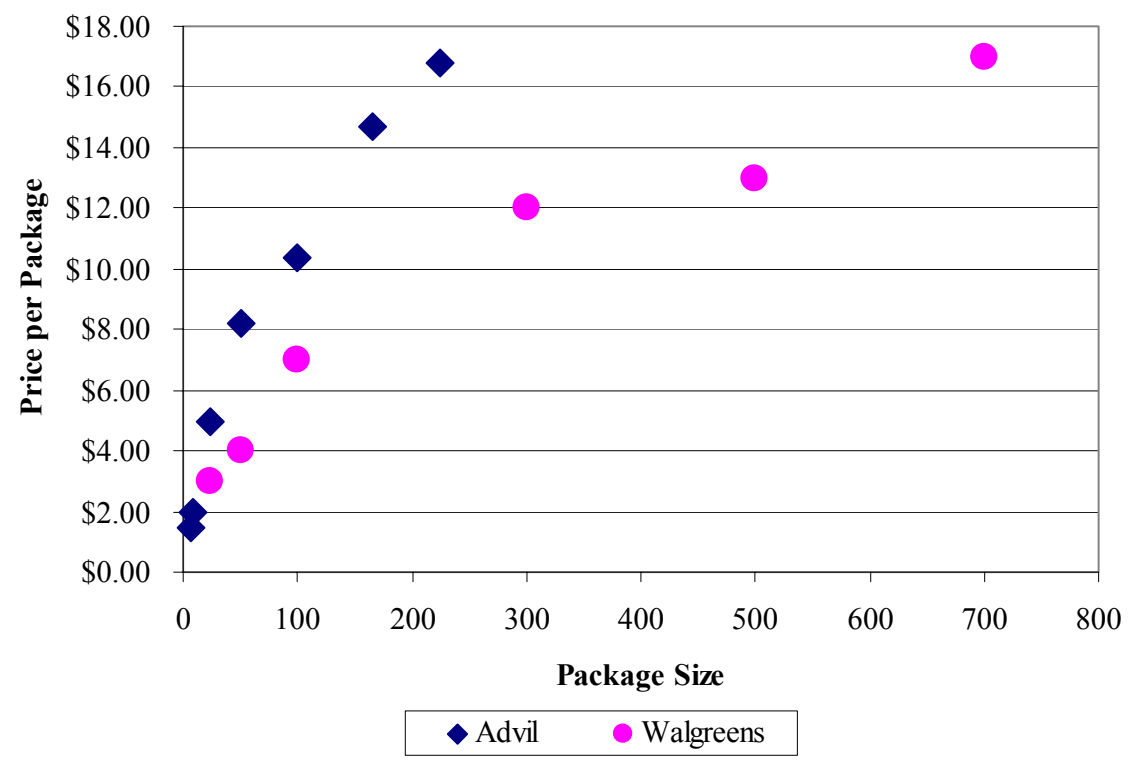

\section{B. Regression Results}

With the above results in hand, we now seek to estimate a single regression equation to characterize the gains consumers realize from purchasing bundled products. The data set we collected had 305 observations. However, these included a variety of dosage forms, such as tablets, liquids, and liqui-gels. To avoid any misspecification from how we treat dosage forms, we restricted attention to tablets or delivery forms typically priced the same as tablets. ${ }^{36}$ This eliminated a large fraction of the medicines containing cough suppressants. Also, the variety of active ingredients to treat coughs is substantially greater than the variety of decongestants, antihistamines, and pain relievers; we were

\footnotetext{
${ }^{36}$ This filter excluded any medicines in liquid or packet form as well as "liqui-gels," which typically sell for a premium. It includes caplets.
} 
Preliminary - Do not redistribute or cite without permission

concerned that we would be unable to get reliable estimates of how each cough

suppressant is priced. As a result, we excluded cough medicines. More precisely, we

restricted attention to tablets in which the active ingredients were limited to the pain

relievers acetaminophen and ibuprofen, the decongestant pseudoephedrine hydrochloride, and the antihistamines chlorpheniramine maleate and diphenhydramine $\mathrm{HCl}^{37}$ This left us with 112 observations.

In order to capture brand effects and the non-linearities in package size documented above, we chose the following specification:

(1) $P_{i}=b_{0}+b_{1} B_{i}+b_{2} T_{i}+b_{3} T_{i}^{2}+b_{4} T_{i} B_{i}+b_{5} T_{i}^{2} B_{i}+\sum_{j=1}^{N} c_{j} Z_{i j}$

where:

$P_{i}$ is the price of package $i$

$\mathrm{T}_{\mathrm{i}}$ is the number of tablets in package $\mathrm{i}$

$\mathrm{B}_{\mathrm{i}}$ is a brand name dummy for package $\mathrm{i}$

$\mathrm{Z}_{\mathrm{ij}}$ is the amount of ingredient $\mathrm{j}$ in package $\mathrm{i}$

The presence of a brand premium raises issues for the effect of bundling in this case. ${ }^{38}$ To see the general issue, consider Table 4.1. For the branded products, the bundle discount is computed as the price of Tylenol Sinus (or Sudafed Sinus Headache) with the sum of the prices of Tylenol Extra Strength and Sudafed Maximum Strength. Both of the

\footnotetext{
${ }^{37}$ Thus, we excluded medicines with cough suppressants. The products we observed contained a much greater variety of cough suppressants than of the other types of ingredients, and we were concerned that we did not have sufficient data to estimate with much accuracy the price effects of each cough suppressant.

${ }^{38}$ A log specification might seem superior for handling the brand premium. There are two reasons, though, why a $\log$ specification is inappropriate for this application. First, interpreting the intercept term as reflecting costs (in a way that will be made precise in the next section) requires a linear specification. Second, the separate ingredients presumably affect costs additively. A log specification would presume that they do so multiplicatively.
} 
Preliminary - Do not redistribute or cite without permission

prices of the component products include a brand premium. ${ }^{39}$ Unless the price of the bundled product includes a double brand premium, then part of the bundle discount reflects a brand premium effect. ${ }^{40}$

Our specification allows the brand premium to be a quadratic function of the number of tablets. While this functional form allows for some flexibility in estimating how companies impose a brand premium, it does not allow the brand premium to be a function of the number of active ingredients. Neither does it allow for the brand premium to depend on the volume of active ingredient per tablet. ${ }^{41}$ We ran regressions in which the brand premium could depend on the number of active ingredients. They provided no evidence that bundled, branded products command a higher (absolute) premium than do unbundled ones. ${ }^{42}$

\footnotetext{
${ }^{39}$ The fact that Tylenol is a Johnson \& Johnson brand while Sudafed is a Pfizer brand is of interest, but a similar issue would arise if the same company owned both.

${ }^{40}$ As we will see, the brand effect accounts for a substantial piece of the bundle discount in this case. Exactly how to interpret this effect would require a better understanding of the source of brand premia than one can currently get from the economics literature. The branding effect could easily be the subject of an entire other paper. In this paper, we merely document the effect and leave its explanation as a potential avenue for future research.

${ }^{41}$ If, for example, one compares the three different strengths of Tylenol described above, it would be of interest to estimate whether the brand premium depends on the number of tablets or on the amount of acetaminophen.

${ }^{42}$ We believe that the branding effect of bundling is potentially of great interest in understanding branding, but we do not pursue it in more detail here because we suspect that it is not a common effect of bundling.
} 
Preliminary - Do not redistribute or cite without permission

Our estimated equation is:

$$
\begin{aligned}
& R_{i}=2.31+0.029 T_{i}-3.3 \times 10^{-5} T_{i}^{2}+0.63 B_{i}+0.054 T_{i} B_{i}-1.23 \times 10^{-4} T_{i}^{2} B_{i} \\
& \begin{array}{lllll}
(7.25)^{*} & (1.89) \quad(4.12)^{*} \quad(1.47) \quad(5.15)^{*} \quad(2.85)^{*}
\end{array} \\
& +0.014 I B_{i}+0.012 A C_{i}+0.065 P_{i}+0.035 C M_{i}+0.042 D I_{i} \\
& \begin{array}{llll}
(0.95) & (0.85) \quad(5.13)^{*} \quad(1.90) & (2.90)^{*}
\end{array} \\
& S=1.24, R^{2}=0.91, F=132.31^{*}, N=112
\end{aligned}
$$

(Note: Values in parenthesis are absolute values of asymptotic t-statistics based on heteroskedasticity-consistent standard errors. * denotes significance at 1 percent (twotailed) level.)

Where:

$\mathrm{IB}_{\mathrm{i}}=$ ibuprofen in package $\mathrm{i}$ in units of $200 \mathrm{mgs}$

$\mathrm{AC}_{\mathrm{i}}=$ acetaminophen in package $\mathrm{i}$ in units of $500 \mathrm{mgs}$

$\mathrm{PH}_{\mathrm{i}}=$ pseudoephedrine hydrochloride in package $\mathrm{i}$ in units of $30 \mathrm{mgs}$

$\mathrm{CM}_{\mathrm{i}}=$ chlorpheneramine maleate in package $\mathrm{i}$ in units of $2 \mathrm{mgs}$

$\mathrm{DI}_{\mathrm{i}}=$ diphenhydramine in package $\mathrm{i}$ in units of $25 \mathrm{mgs}$

The coefficients on the active ingredients are all positive, although only the ones on the pseudoephedrine $\mathrm{HCl}$ and diphenhydramine variables are significant. The coefficients on the amount of acetaminophen and ibuprofen are small and imprecisely determined. That they are small makes sense. The price of both bulk acetaminophen and bulk ibuprofen is approximately $\$ 8 / \mathrm{kg}^{43}$ which would contribute $\$ 0.004$ per $500 \mathrm{mg}$ acetaminophen tablet and $\$ 0.0016$ per $200 \mathrm{mg}$ ibuprofen tablet.

These regressions reveal three primary sources of gains to consumers from buying bundled products. The first is the intercept term of $\$ 2.31$, which is highly statistically significant. The purchaser of the bundled product pays one fixed component in the price 
Preliminary - Do not redistribute or cite without permission

term. Purchasers of the two separate products would pay two. The second source of gains is associated with the number of tablets. It is $0.029 T_{i}-3.3 \times 10^{-5} T_{i}^{2}$. Again, purchasers of the bundled product pay this component once. Purchasers of two separate products would pay it twice. This component of the savings comes to $\$ 0.67$ for 24 -tablet packages and \$1.29 for 48-tablet packages. Thus, the cost-based savings absent of brand effects are $\$ 2.98$ for 24 tablet packages and $\$ 3.60$ for 48 tablet packages. The third source of gains applies only to purchasers of branded products. It is given by $0.63+0.54 T_{i}-0.00012$ $T_{i}^{2}$. It amounts to $\$ 1.84$ and $\$ 2.92$ for 24 -tablet and 48-tablet packages, respectively. ${ }^{44}$

\section{Modeling the Bundle Discount}

This case was selected because it has features that our model is designed to capture. The different medications can be (and are) sold both separately and in combination. The assumption of diverse consumer preferences seems applicable. To use the example in Table 4.1, some people have a headache and want just acetaminophen. Some people have a cold and want just a decongestant. Some have a sinus headache and want both. ${ }^{45}$ Because of savings in packaging, making tablets, and transactions expense, the marginal cost of the bundled product is less than the sum of the marginal costs of the

\footnotetext{
${ }^{43}$ See http://www.the-innovation-group.com/ChemProfiles/Acetaminophen.htm and www.tulika.com/exportprices.htm (accessed April 25, 2005).

${ }^{44}$ These estimates are for the savings from buying a bundled medicine with two active ingredients as compared with buying the components separately. The effect would be twice as large for products with three active ingredients as compared with buying all three separately.

${ }^{45}$ The model assumes that consumers who want just one component are willing to buy it as part of the bundle. In economics terminology, we assume free disposal. That plainly does not apply to this case. Many people with just a headache would no doubt prefer just a pain reliever to a pain reliever plus decongestant combination.
} 
Preliminary - Do not redistribute or cite without permission

unbundled items. Given that mixed bundling prevails, ${ }^{46}$ fixed costs seem not to be so large as to prevent a good that people want from being offered. Yet, some fixed cost is present. Each additional stock-keeping unit (sku) imposes a cost on a retailer as it must order the product, maintain inventories, and so on. In addition, each distinct product sold by a retailer must occupy a shelf slot. The cost of these slots is an example of what accountants refer to as "semi-fixed" or "step" costs. They are not fixed with respect to all levels of output, but they are incurred in discrete units (or "steps"). Whether or not such costs should be deemed primarily fixed or primarily marginal depends on the size of the steps relative to total demand. We do not have the information one would need to determine whether shelf space should be considered a fixed or marginal expense, but it is at least plausible that it is more nearly fixed. ${ }^{47}$

The substantial brand premia in the model might cast doubt on the applicability of the contestability assumption. We have two responses. First, our econometric specification allows us to estimate the size of the brand premium and thereby remove it from our estimate of costs. Second, even if, say, Tylenol is a dominant brand in acetaminophen, a monopoly model may not be the best for understanding its pricing behavior. Like any modeling assumption, the contestability assumption is meant as an approximation, not literal truth. The implication of the assumption is that prices are

\footnotetext{
${ }^{46}$ This comment requires some qualification. To take one example, Johnson \& Johnson sells acetaminophen alone and acetaminophen in combination with pseudoephedrine $\mathrm{HCl}$. It does not sell pseudoephedrine $\mathrm{HCl}$ alone. While this is technically tying from the standpoint of the company, the market outcome does not entail tying. One can purchase pseudoephedrine $\mathrm{HCl}$. Moreover, because Johnson \& Johnson does sell Tylenol without any additional active ingredients, its tying is not the sort that could raise antitrust concerns.

${ }^{47}$ One relevant piece of information is the number of shelf slots devoted to an item. In grocery stores in the United States, it is common to observe multiple slots devoted to two-liter bottles of Coca-Cola, and the number of slots increases when Coca-Cola is a sale item. In that case, the shelf space should be treated as a marginal cost. When just one shelf slot is devoted to an item, there is a stronger case for treating shelf space as a fixed cost.
} 
Preliminary - Do not redistribute or cite without permission

driven primarily by costs with the elasticity of demand playing a less important role. The rationale for the assumption is that the firm faces enough competitive constraints from both actual competition (other pain relievers like ibuprofen and generic acetaminophen) and potential competition (other pharmaceutical companies that are plainly capable of producing the product) to place strict limits on the extent to which prices can exceed costs.

The choice between a competitive model and a monopoly model is particularly crucial because the result we are most interested in explaining is the bundle discount. We interpret the bundle discount as reflecting costs. The models of bundling as price discrimination might seem to suggest an alternative, demand-based explanation. In comparing the competing explanations, one must be clear on what the model must explain. The key stylized fact we have established is not just that there is a bundle discount, but that it is so large. A cost-based model provides a simple explanation. Since the active ingredients represent a small portion of the cost of the product, the cost of producing and selling a package of tablets with, say, acetaminophen and pseudophedrine hydrochloride is only slightly greater than the cost of producing and selling a package of tablets with acetaminophen alone. Because the bundled products likely provide convenience, we question whether a monopoly price discrimination model would imply a bundle discount (as opposed to a premium) at all, much less one as steep as the one we observe.

In any event, our primary purpose here is not to assert that the model is a complete explanation but, rather, to advance the techniques for assessing whether the set of product offerings is optimal. Even assuming that the bundle discount is cost-based, its 
Preliminary - Do not redistribute or cite without permission

welfare implications are more complicated than one might initially expect. To see this point, we need to present the model more formally.

In the simplest version, ${ }^{48}$ let $\mathrm{X}_{1}$ be the number of people who want just good $1, \mathrm{X}_{2}$ be the people who want just good 2 , and $\mathrm{X}_{\mathrm{B}}$ be the number of people who want both. Let $\mathrm{F}$ be the fixed cost of a product offering, $\mathrm{c}_{1}$ and $\mathrm{c}_{2}$ be the marginal cost of goods 1 and 2 , respectively, and $\mathrm{c}_{\mathrm{B}}$ be the marginal cost of the bundle with $\mathrm{c}_{\mathrm{B}} \leq \mathrm{c}_{1}+\mathrm{c}_{2}$. Letting $\mathrm{p}_{1}, \mathrm{p}_{2}$, and $\mathrm{p}_{\mathrm{B}}$ be the prices of goods 1 and 2 and of the bundle, then the contestable prices are:

$$
p_{i}=c_{i}+\frac{F}{X_{i}} \quad i \in\{1,2, B\}
$$

and the discount for the bundle (DB) is given by:

$$
\mathrm{DB} \equiv p_{1}+p_{2}-p_{B}=c_{1}+c_{2}-c_{B}+\frac{F}{X_{1}}+\frac{F}{X_{2}}-\frac{F}{X_{B}}
$$

As equation (4) makes clear, there are two possible sources of the bundle discount. One is marginal cost savings, $\mathrm{c}_{1}+\mathrm{c}_{2}-\mathrm{c}_{\mathrm{B}}$. The other concerns fixed costs. A customer who buys the two components separately contributes to two fixed costs; the purchaser of the bundled product only contributes to one.

Without knowing $\mathrm{X}_{1}, \mathrm{X}_{2}$, and $\mathrm{X}_{\mathrm{B}}$, we cannot be sure that the bundle discount is attributable at all to fixed costs. As a practical matter, however, it likely is. To cover its costs, a retailer must "mark up" the prices of the items it sells. Unless the retail mark-up on the bundled item is at least the sum of its mark-ups on the components - and there is no reason to suppose that it is - then part of the customer savings reflects retail mark-ups.

\footnotetext{
${ }^{48}$ In this version, demand by each group is treated as being perfectly inelastic within the range of prices that might prevail. See the appendix to David S. Evans and Michael A. Salinger, "The Role of Cost in Determining When Firms Offer Bundles and Ties” (2004 Working paper, available at http://ssrn.com/abstract=550884) for an extension to price-sensitive demand.
} 
Preliminary - Do not redistribute or cite without permission

A key result in Evans and Salinger (2004) is that mixed bundling can occur even if it is not the set of offerings that minimizes total costs. Under mixed bundling, there has to be a bundle discount, ${ }^{49}$ but the private savings from the bundle discount do not necessarily represent social savings. If we let SB be the cost savings from offering the bundle $^{50}$ (stated on a per-customer basis to aid comparability with the bundle discount), then:

$$
S B=c_{1}+c_{2}-c_{B}-\frac{F}{X_{B}}=D B-\frac{F}{X_{1}}-\frac{F}{X_{2}}
$$

The first three terms of (5), which reflect marginal costs, are identical to (4). With the marginal costs, private savings reflect social savings. The last term of (5) is also the last term of (4). There is a social fixed cost of offering the bundle that must be subtracted from the marginal cost savings. In a contestable market, purchasers of the bundle bear this cost as well. The difference between (4) and (5) comes from the two terms in (4) that reflect the average fixed costs of the two component goods. If those who want both components were to buy them separately, the prices they would pay would reflect these fixed costs. When they buy the bundle instead, they get a private benefit from not contributing to those fixed costs, but there is no corresponding social benefit because the fixed costs of the components are not reduced.

The last part of equation (5) provides a simple approach to inferring the cost savings from the bundle (under mixed bundling) from the bundle discount. It says that the cost savings (per consumer of the bundle) are the bundle discount minus the average fixed cost portion of the prices of the two separate goods.

\footnotetext{
${ }^{49}$ Otherwise, consumers who want both components would not buy the bundle.

${ }^{50} \mathrm{SB}$ represents the savings from offering the bundle given that goods 1 and 2 are also offered.
} 
Preliminary - Do not redistribute or cite without permission

The following pair of examples illustrates the point:

$$
\begin{aligned}
& \text { Example 1: } c_{1}=c_{2}=2, c_{B}=2.9, F=0, X_{1}=X_{2}=X_{B}=100 \\
& \text { Example 2: } c_{1}=c_{2}=1, c_{B}=1.9, F=100, X_{1}=X_{2}=X_{B}=100
\end{aligned}
$$

In both cases, the unique sustainable outcome is mixed bundling with $\mathrm{p}_{1}=\mathrm{p}_{2}=2$ and $\mathrm{p}_{\mathrm{B}}=$ 2.9. ${ }^{51}$ The bundle discount is substantial. In example 1, the bundle discount entirely reflects social savings. The total cost of meeting demand with mixed bundling is 690 . The cost of meeting demand with components selling would be 800 , or 110 more. In example 2 , the total cost of meeting demand with mixed bundling is also 690 , just as in example 1 . In contrast to example 1, however, the total cost of meeting demand with components selling would be only $600 .{ }^{52}$ Unless the bundled product provides convenience for the customers who want both items, the mixed bundling would be inefficient despite the substantial bundle discount.

A similar point applies to the individual components. Under mixed bundling, the price of each component has to be less than the price of the bundle, ${ }^{53}$ but that does not imply that offering the separate good lowers costs. If we let $\mathrm{DC}_{\mathrm{i}}$ and $\mathrm{SC}_{\mathrm{i}}$ be the discount

\footnotetext{
${ }^{51}$ This point should be obvious for example 1. For example 2, the prices under pure components selling would be $\$ 1.50$ (calculated as $1+100 / 200$ ) for each item. Customers who buy both pay a total of $\$ 3$. This outcome is not sustainable because it is susceptible to entry with the bundle at a price of $\$ 2.9$. Similarly, pure bundling is not sustainable. The price under pure bundling would be $2.9+100 / 300 \approx 3.23$. That price is not sustainable because an entrant could break even selling either component at a price of $\$ 3$.

${ }^{52}$ In example 2, there are some marginal cost savings from bundling. If there were no marginal cost savings from bunding, then mixed bundling would still be sustainable (and inefficient), but it would not be the unique sustainable outcome. Components selling would be sustainable as well. Mixed bundling can be the unique sustainable outcome with no marginal cost savings from bundling if $X_{B}$ is greater than the geometric mean of $X_{1}$ and $X_{2}$. For a more complete explanation, see David S. Evans and Michael A. Salinger, "The Role of Cost in Determining When Firms Offer Bundles and Ties" (2004 Working paper, available at http://ssrn.com/abstract $=550884$ ).

${ }^{53}$ Another simplifying assumption of our model is that consumers who want just one of the goods get no utility or disutility from the other good. As a result, they view the bundle as a perfect substitute for the good they want. That assumption does not apply to our application, since, for example, many consumers who want just a pain reliever would prefer not to have to take a decongestant as well. Just as it would be easy to incorporate a convenience value for the bundle in the model, we could also assume that consumers who want just one component are willing to pay a premium not to have it bundled with the other.
} 
Preliminary - Do not redistribute or cite without permission

and cost savings (per customer of good i) of offering good $\mathrm{i}$ (given that the bundle is offered), we have:

$$
\begin{aligned}
& D C_{i} \equiv p_{i}-p_{B}=c_{B}-c_{i}+\frac{F}{X_{B}}-\frac{F}{X_{i}} \\
& S C_{i}=c_{B}-c_{i}-\frac{F}{X_{i}}=D C_{i}-\frac{F}{X_{B}}
\end{aligned}
$$

Equation (7) says that to infer the cost savings from having a component available separately, one must subtract the average fixed cost component of the price of the bundled good from the component discount.

Referring back to our pricing regression, the bundle discount has three components: the intercept, the coefficients on the tablet variables, and the coefficients on the brand-name variables. As noted above, we focus on the first two. The estimated equation distinguishes between price components that are fixed and variable with respect to package size. Within our model, however, the key distinction is whether or not the costs are fixed or marginal with respect to a customer. The cost of placing active ingredients into tablets and, to some extent, the cost of the package itself, are examples of costs that are marginal with respect to both package size and to the customer. To the extent that package costs rise less than proportionately with the number of tablets, however, then, part of packaging cost would be reflected in our intercept term. Even though this component is fixed with respect to package size, it is variable with respect to the customer. ${ }^{54}$ Another example of this kind of cost is the cost of the time it takes a clerk

\footnotetext{
${ }^{54}$ Our argument that the packaging cost is reflected at least partially in the intercept term does not require that the packaging cost equation literally has a positive intercept. If we observed packaging costs directly, our estimates of the marginal cost savings from bundling would be based on the cost of a package of a given size, such as 24 tablets or 48 tablets. Taken, literally, the intercept reflects the cost of a 0-tablet package, which is irrelevant for computing the gains from bundling. Given our choice of a quadratic
} 
Preliminary - Do not redistribute or cite without permission

to process a transaction. Finally, some costs are fixed both with respect to the customer and to the size of the package. The costs of having an additional sku and, to a large extent, the cost of shelf space are examples. ${ }^{55}$

\section{Decomposing Fixed and Marginal Cost Effects with Package Size Pricing Regularities}

We now show how to use the package-size regularities documented in Section IV to decompose the bundle and component discounts into marginal cost and fixed cost components. This decomposition will then allow us to measure the (possibly negative) cost savings (per customer) from each product.

Our interpretation of quantity discounts as being cost-based raises issues similar to whether the bundle discount reflects costs or price discrimination. The theory of quantity dependent monopoly pricing would seem to provide an alternative explanation. As with the bundle discount, there are several responses. First, costs provide a compelling explanation. The pills themselves represent a relatively small fraction of the cost. Packaging costs appear to be significant and subject to scale economies. Many aspects of the transaction cost would seem to be independent of the size of the package. Second, all the products come in a relatively small number of package sizes, which is the phenomenon that we exploit. Even in a monopoly model, it would be hard to explain that without reference to some fixed cost of a product offering. Third, consider pseudophederine hydrochloride, which generally comes in packages of 24 and 48 . It seems hard to rule out the possibility that some people would like to buy 72 . Theories of

functional form, however, the cost of a pacakge of a particular size would be reflected in part in the intercept. 
Preliminary - Do not redistribute or cite without permission

non-linear pricing would generally predict that they should be given a lower price per tablet than the people who wish to purchase 48 . Whether they bought one package of 48 and one of 24 or two packages of 48 , their price per pill that they want would be higher than for people who wish to purchase 48 tablets.

\section{A. Theory}

The key to understanding the size of the the product-specific fixed costs is to observe products that could conceivably exist but do not. ${ }^{56}$ In the cases we have considered, product tying does not occur. Among the products sold in bundled form that we have considered, all the component medicines are available separately. Rather than looking to products that do not exist, we look to package sizes that are not offered. The price-package size relationships presented in Figures 3.1 and 3.2 provide evidence of economies of package size. As a consequence, customers who want a large quantity are better off buying one large package than several smaller ones. However, not all possible package sizes are offered. For example, the Walgreens in question sold Extra Strength Tylenol in packages of 24, 100, 150, 200, and 225. It did not, however, sell packages of 175. There does not seem to be any reason to suppose that there were no customers who would most prefer to buy 175 . Such a customer must choose between buying a package

\footnotetext{
${ }^{55}$ It is possible that some costs might be variable with respect to package size but fixed with respect to the customer. This could happen if, for example, larger packages require more shelf space. Our procedure for estimating the component of price that covers fixed costs ignores this possibility.

${ }^{56}$ Other papers that use or suggest an analogous approach to estimating fixed costs are Timothy F. Bresnahan and Peter C. Reiss, "Do Entry Conditions Vary Across Markets?" Brookings Papers on Economic Activity: Special Issue on Microeconomics (3) (1987): 833-871; Ariel Pakes and Paul McGuire, "Computing Markov-Perfect Nash Equilibria: Numerical Implications of a Dynamic Differentiated Product Model," RAND Journal of Economics 25(4) (1994): 555-589e; Richard Ericson and Ariel Pakes, "MarkovPerfect Industry Dynamics: A Framework for Empirical Work.” ReStud 62 (1) (1995): 53-82; Chaim Fershtman and Ariel Pakes, "A Dynamic Oligopoly with Collusion and Price Wars," RAND Journal of Economics 31(2) (2000): 207-236; Eugenio Miravete, "Are all those Calling Plans Really Necessary? The Limited Gains From Complex Tariffs" (CEPR Discussion Paper No. 4237, 2004); Ariel Pakes, Michael
} 
Preliminary - Do not redistribute or cite without permission

of 200 and wasting 25 of them or buying a package of 150 and supplementing the package of 150 with, say, another package of $24 .{ }^{57}$ Given the economies of package size, neither of these solutions would give the customer as good a price as he would get if a package of 175 were available on the market.

To estimate the cost factor that prevents the package of 175 from being introduced, we need to introduce some theory that extends the contestability analysis from our previous paper. The general approach is to view the set of products offered and their prices as a sustainable market outcome, which means that entry with another product (in this case, a different package size) is not profitable. Let $\mathrm{Q}_{\mathrm{i}}, \mathrm{Y}_{\mathrm{i}}$, and $\mathrm{P}_{\mathrm{i}}$ be the package size, number of purchasers, and price of package $i$ for $i=1$ or 2 with $Q_{1}<Q_{2}$. Let $C($.$) be the marginal cost$ of selling a package of a particular size to an extra customer. Then, the contestability result that price equals average cost implies:

$$
P\left(Q_{i}\right)=\frac{F}{Y_{i}}+C\left(Q_{i}\right)
$$

Let $\bar{Q}$ be the average of $\mathrm{Q}_{1}$ and $\mathrm{Q}_{2}$, and assume that if $\bar{Q}$ were offered at a lower price, half the people who buy $\mathrm{Q}_{2}$ would buy $\bar{Q}$ instead. The price at which it could be offered would be:

$$
P(\bar{Q})=\frac{2 F}{Y_{2}}+C(\bar{Q})
$$

We now need to make the simplifying assumptions that $\mathrm{Q}_{1}$ and $\mathrm{Q}_{2}$ are close enough to each other that a linear approximation of the marginal cost function is reasonable and that $Y_{1}=Y_{2}$.

Ostrovsky, and Steven T Berry, "Simple Estimators for the Parameters of Discrete Dynamic Games (with Entry/Exit Samples)" (NBER Working Paper No. W10506, 2004).

${ }^{57}$ This choice would, of course, leave the consumer one pill short of his desired quantity. 
Preliminary - Do not redistribute or cite without permission

With these additional assumptions, it is straightforward to show that the condition that makes it impossible to offer the package size half way between $\mathrm{Q}_{1}$ and $\mathrm{Q}_{2}$ is. ${ }^{58}$

$$
\frac{F}{Y_{2}}>\frac{P_{2}-P_{1}}{2}
$$

\section{B. Results}

The left-hand side of (10) is the component of the price that goes to covering the fixed cost. Each successive pair of package sizes yields an estimate. Figure 6.1 shows a histogram of our estimates of the lower bounds of the fixed costs taken from the data underlying Figures 4.1 and 4.2. The mean value is $\$ 1.33$, the median is $\$ 1.20$, and the modal range is $\$ 1.00$ to $\$ 1.50$. Taking the median as our estimate, we estimate that $\$ 1.20$ of each package price represents a contribution to fixed costs.

\footnotetext{
${ }^{58}$ This condition only insures that the existing offering is sustainable with respect to entry half way between two package sizes that are offered. More generally, one might impose the condition that the offering be sustainable with respect to all possible intermediate package sizes. In doing so, however, one would probably not make our simplifying assumptions about marginal cost and demand.
} 
Preliminary - Do not redistribute or cite without permission

Figure 6.1. Estimated Lower Bounds of Offering Average Fixed Costs

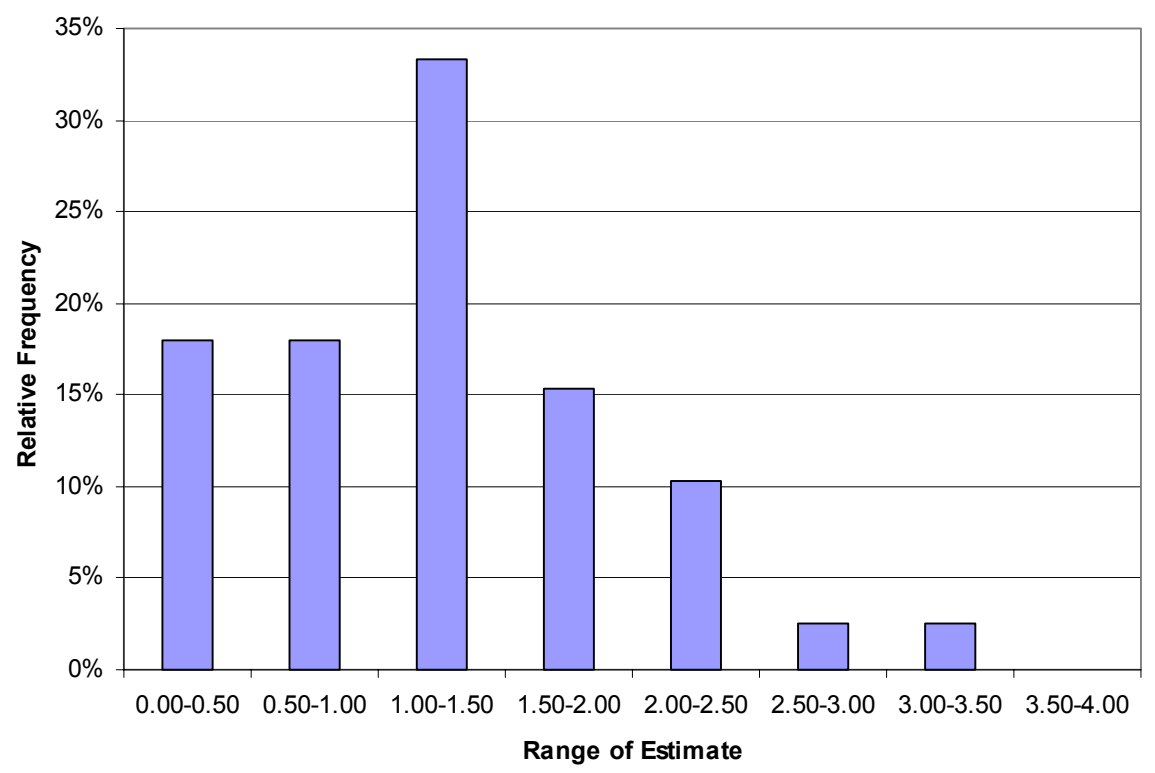

In Section II, we estimated a cost-based savings ${ }^{59}$ of $\$ 2.98$ and $\$ 3.60$ for 24-count and 48-count packages of tablets with two active ingredients. Given our estimate of $\$ 1.20$ as the part that reflects a contribution to fixed costs, the implied marginal cost savings are $\$ 1.78$ and $\$ 2.40$. Using equation (5), we estimate that the cost savings per customer from the bundled products are $\$ 0.58$ and $\$ 1.20$, respectively.

Both the private and net savings would be larger for tablets that combine three active ingredients. The private savings are twice as large, so they are $\$ 5.96$, which reflects $\$ 3.56$ in marginal cost savings and $\$ 2.40$ in average fixed cost. From the

\footnotetext{
${ }^{59}$ By cost-based savings, we mean those not related to branding effects.
} 
Preliminary - Do not redistribute or cite without permission

marginal cost savings of $\$ 3.56$, which represents a social benefit, we must subtract the

$\$ 1.20$ average fixed cost of the additional offering. The net cost savings are $\$ 2.36$.

The gains from bundling would also be larger for larger packages. For example, for packages of 48 tablets, our regression equation implies private gains of $\$ 3.60$ and \$7.20 for tablets that combine two ingredients and three ingredients, respectively. The net effect on costs would then be savings of $\$ 1.20$ and $\$ 3.60$ for the bundled products. ${ }^{60}$

We can also use equation (8) to estimate whether there are cost savings from offering the stand-alone products. Consider again the example in Table 4.1. The regression results indicate that for people who want just acetaminophen, the marginal cost of buying acetaminophen bundled with pseudoephedrine hydrochloride would be $\$ 0.065 \cdot 24=\$ 1.56$. As this exceeds our estimate of the average fixed cost of $\$ 1.20$, we estimate the cost savings from having the stand-alone acetaminophen product to be $\$ 0.36$. For consumers who want just pseudoephedrine hydrochloride, the regression results imply that the marginal cost of buying it bundled with acetaminophen would be $\$ 0.012$. $24=\$ 0.29$. As this incremental cost is less than the average fixed cost, it would lower costs not to offer the 24-tablet package of just pseudoephendrine hydrochloride. In other words, tying would lower costs. ${ }^{61}$

\footnotetext{
${ }^{60}$ The calculations are $\$ 3.60-2 \cdot \$ 1.20=\$ 1.20$ and $\$ 7.20-3 \cdot \$ 1.20=\$ 3.60$.

${ }^{61}$ Assuming that the groups that want just pseudoephedrine $\mathrm{HCl}$ and that want the bundled product are of equal size, tying would also be sustainable. By pricing the bundled product to attract the group that wants just the decongestant, the average fixed costs could be reduced from $\$ 1.20$ to $\$ 0.60$. This $\$ 0.60$ price reduction would more than offset the $\$ 0.29$ marginal cost associated with the extra active ingredient.
} 
Preliminary - Do not redistribute or cite without permission

\section{Conclusions}

Any economist who looks at the state of debate on the anticompetitive use of tying should find it quite unsettling. On the one hand, there is an economics literature that assumes away all efficiencies and documents, unsurprisingly in light of modern game theory, that it is possible to locate assumptions under which tying is anticompetitive. We have no doubt that firms can sometimes engage in tying that reduces consumer welfare, but the economics literature is not much help in identifying these situations. On the other hand, there is a case law that places much of the weight of the tying analysis on whether a product is a single product or a tie of two separate products. The Jefferson Parish test seems to suggest that one mainly needs to look at whether there is material demand for the tied product. The D.C. Circuit Court of Appeals provided an elegant (although only weakly supportive) rationale for this test: it is supposed to be a proxy for whether the "tie" is efficient or not; if there is no demand then the markets have revealed that a single product consisting of the tying and tied goods is efficient. Little thought is required to come up with countless examples that demonstrate that this is not a powerful test (i.e., it leads to many errors). Competitive markets provide shoes with shoelaces, cars with tires, men's suits with tailoring, newspapers with television listings, and so forth.

Economists might criticize the courts for sloppy analysis, but one looks at the economics literature in vain to see our profession providing the antitrust authorities or the courts with much useful guidance. There is a vast gulf between the Chicago School view that "there's a single monopoly profit so it must be efficient" to the game theoretic view that "without efficiencies it could be anticompetitive." In between, there is essentially no 
Preliminary - Do not redistribute or cite without permission

empirical evidence that would explain what product configurations emerge in reasonably competitive markets. And one sees this divide in the court cases in which defendants offer explanations for tying that are based on little empirical analysis, or theoretical reasoning, and which courts and antitrust authorities quickly dismiss as being gratuitous (see our earlier discussion of Jefferson Parish).

Our contribution in this chapter and our companion articles is twofold. First, we have provided a theoretical framework that, while admittedly being based on assumptions that one can question and future work should modify, can be empirically implemented. Second, and this is the specific purpose of this paper, we have shown how it is possible to estimate the key primitives of the model at least for the example we have chosennamely the extent of offering-specific fixed and variable costs of a product. Both the framework and the empirical results highlight the importance of the fixed cost of offering particular product configurations in "pretty competitive" markets. Costs play a more central role in this analysis than in the existing literature.

Of course, this trilogy of articles provides only a first step. On the theoretical side, alternatives to the contestability assumption need to be explored and it would be useful to embed the analysis in a model in which the degree of market power could vary. On the empirical side, we see two priorities. One is to improve the estimates of the fixed costs of product offerings. ${ }^{62}$ The other is to estimate the convenience value from bundling and unbundling. ${ }^{63}$ Neither will be easy; but given that the theory identifies

\footnotetext{
${ }^{62}$ We acknowledge that the approach we use in this paper is crude.

${ }^{63}$ The difficulty of doing so in this case is that when customers can buy bundled goods at a discount, it is hard to observe how much more they would be willing to pay for the bundled product if they had to. In theory, one could estimate the convenience premium indirectly by combining the increased quantity demanded with the elasticity of demand, but neither of those would be easy to estimate either.
} 
Preliminary - Do not redistribute or cite without permission

these factors as being key to both the private decision to bundle and tie and to the welfare analysis of these practices, some effort to overcome the challenges is warranted.

The general approach we have applied to tying could be usefully applied to other business practices that are sometimes questioned as being anticompetitive. That approach involves developing a positive theory for why certain practices emerge in "pretty competitive" environments and ascertaining the extent to which efficiency helps explain those practices. The theory is designed to encourage empirical investigation.

At this stage of development this approach is subject to the same criticism as the game-theoretic work on tying. Just as that approach assumes efficiency away, our approach assumes anticompetitive explanations away. Over time, industrial organization economists need to develop theories that can account for both pro-competitive and anticompetitive explanations and that can be tested empirically. 
Preliminary - Do not redistribute or cite without permission

\section{References}

Areeda, Philip and Herbert J. Hovenkamp. Antitrust Law: An Analysis of Antitrust Principles and Their Application. 2nd Ed. New York: Aspen Law \& Business, 2000.

Baumol, William J. 1982. "Contestable Markets: An Uprising in the Theory of Industry Structure.” American Economic Review 72: 1-15.

Baumol, William J., John C. Panzar, and Robert D. Willig. 1982. Contestable Markets and the Theory of Industry Structure (New York: Harcourt Brace Jovanovich, Inc.).

Bresnahan, Timothy F. and Peter C. Reiss. 1987. "Do Entry Conditions Vary Across Markets?" Brookings Papers on Economic Activity: Special Issue on Microeconomics (3): 833-871.

Crawford, Gregory. 2004. "The Discriminatory Incentives to Bundle: The Case of Cable Television." University of Arizona, Working Paper.

Director, Aaron and Edward H Levi. 1956. "Law and the Future: Trade Regulation," Northwestern University Law Review 51 (May-June): 281-96.

Ericson, Richard and Ariel Pakes. 1995. "Markov-Perfect Industry Dynamics: A Framework for Empirical Work.” ReStud 62 (1): 53-82.

Evans, David S. and Michael A. Salinger. 2004. "The Role of Cost in Determining When Firms Offer Bundles and Ties." http://ssrn.com/abstract=555818.

Evans, David S. and Michael A. Salinger. 2005. "Why Do Firms Bundle and Tie? Evidence from Competitive Markets and Implications for Tying Law." Yale Journal on Regulation 22 (1): 37-89.

Evans, David S. and A. Jorge Padilla. 2005, "Designing Antitrust Rules for Assessing Unilateral Practices: A Neo-Chicago Approach." University of Chicago Law Review, Forthcoming.

Fershtman, Chaim and Ariel Pakes. 2000. "A Dynamic Oligopoly with Collusion and Price Wars." RAND Journal of Economics 31(2): 207-236.

Grimes, Warren S. 2002. "The Antitrust Tying Law Schism: A Critique of Microsoft III and A Response to Hylton and Salinger." Antitrust Law Journal 70: 199230 .

Hylton, Keith N. and Michael A. Salinger. 2001. "Tying Law and Policy: A Decision Theoretic Approach.” Antitrust Law Journal 69: 469. 
Preliminary - Do not redistribute or cite without permission

Kallaugher, John and Brian Sher. 2004. "Rebates Revisited: Anti-Competitive Effects and Exclusionary Abuse Under Article 82." European Competition Law Review 25(5): 263-285.

Kamann, Hans-Georg and Ellen Bergmann. 2005. "The Granting of Rebates by Market Dominant Undertakings under Article 82 of the EC Treaty." European Competition Law Review 26(2): 83-89.

Miravete, Eugenio. 2004. "Are all those Calling Plans Really Necessary? The Limited Gains From Complex Tariffs.” CEPR Discussion Paper No. 4237.

http://ssrn.com/abstract=509009.

Morrison, Steven A. and Clifford Winston. 1987. "Empirical Implications and Tests of the Contestability Hypothesis." Journal of Law and Economics 30(1): 53-66.

Pakes, Ariel and Paul McGuire. 1994. "Computing Markov-Perfect Nash Equilibria: Numerical Implications of a Dynamic Differentiated Product Model.” RAND Journal of Economics 25(4): 555-589.

Pakes, Ariel, Michael Ostrovsky, and Steven T Berry. 2004. "Simple Estimators for the Parameters of Discrete Dynamic Games (with Entry/Exit Samples)." NBER Working Paper No. W10506. http://ssrn.com/abstract=552302.

Rubinfeld, Daniel L. 2005. "3M's Bundling Rebates: An Economic Perspective," Chicago Law Review 72: 243-264.

Stigler, George J. “A Note on Block Booking”, in The Organization of Industry. George J. Stigler, Ch. 15 Chicago: University of Chicago Press (1983).

Tirole, Jean. The Theory Of Industrial Organization. Cambridge, MA: The MIT Press, 1988.

Whinston, Michael. 1990. "Tying, Foreclosure, and Exclusion." American Economic Review 80: 837-859. 


\section{CESifo Working Paper Series}

(for full list see www.cesifo-group.de)

1457 Margarita Katsimi and Thomas Moutos, Inequality and Relative Reliance on Tariffs: Theory and Evidence, April 2005

1458 Monika Bütler, Olivia Huguenin and Federica Teppa, Why Forcing People to Save for Retirement may Backfire, April 2005

1459 Jos Jansen, The Effects of Disclosure Regulation of an Innovative Firm, April 2005

1460 Helge Bennmarker, Kenneth Carling and Bertil Holmlund, Do Benefit Hikes Damage Job Finding? Evidence from Swedish Unemployment Insurance Reforms, May 2005

1461 Steffen Huck, Kai A. Konrad and Wieland Müller, Merger without Cost Advantages, May 2005

1462 Louis Eeckhoudt and Harris Schlesinger, Putting Risk in its Proper Place, May 2005

1463 Hui Huang, John Whalley and Shunming Zhang, Trade Liberalization in a Joint Spatial Inter-Temporal Trade Model, May 2005

1464 Mikael Priks, Optimal Rent Extraction in Pre-Industrial England and France - Default Risk and Monitoring Costs, May 2005

1465 François Ortalo-Magné and Sven Rady, Heterogeneity within Communities: A Stochastic Model with Tenure Choice, May 2005

1466 Jukka Pirttilä and Sanna Tenhunen, Pawns and Queens Revisited: Public Provision of Private Goods when Individuals make Mistakes, May 2005

1467 Ernst Fehr, Susanne Kremhelmer and Klaus M. Schmidt, Fairness and the Optimal Allocation of Ownership Rights, May 2005

1468 Bruno S. Frey, Knight Fever - Towards an Economics of Awards, May 2005

1469 Torberg Falch and Marte Rønning, The Influence of Student Achievement on Teacher Turnover, May 2005

1470 John Komlos and Peter Salamon, The Poverty of Growth with Interdependent Utility Functions, May 2005

1471 Hui Huang, Yi Wang, Yiming Wang, John Whalley and Shunming Zhang, A Trade Model with an Optimal Exchange Rate Motivated by Current Discussion of a Chinese Renminbi Float, May 2005

1472 Helge Holden, Lars Holden and Steinar Holden, Contract Adjustment under Uncertainty, May 2005 
1473 Kai A. Konrad, Silent Interests and All-Pay Auctions, May 2005

1474 Ingo Vogelsang, Electricity Transmission Pricing and Performance-Based Regulation, May 2005

1475 Spiros Bougheas and Raymond Riezman, Trade and the Distribution of Human Capital, June 2005

1476 Vesa Kanniainen, Seppo Kari and Jouko Ylä-Liedenpohja, The Start-Up and Growth Stages in Enterprise Formation: The "New View" of Dividend Taxation Reconsidered, June 2005

1477 M. Hashem Pesaran, L. Vanessa Smith and Ron P. Smith, What if the UK had Joined the Euro in 1999? An Empirical Evaluation Using a Global VAR, June 2005

1478 Chang Woon Nam and Doina Maria Radulescu, Effects of Corporate Tax Reforms on SMEs' Investment Decisions under the Particular Consideration of Inflation, June 2005

1479 Panos Hatzipanayotou, Sajal Lahiri and Michael S. Michael, Globalization, CrossBorder Pollution and Welfare, June 2005

1480 John Whalley, Pitfalls in the Use of Ad valorem Equivalent Representations of the Trade Impacts of Domestic Policies, June 2005

1481 Edward B. Barbier and Michael Rauscher, Trade and Development in a Labor Surplus Economy, June 2005

1482 Harrie A. A. Verbon and Cees A. Withagen, Tradable Emission Permits in a Federal System, June 2005

1483 Hendrik Hakenes and Andreas Irmen, On the Long-Run Evolution of Technological Knowledge, June 2005

1484 Nicolas Schmitt and Antoine Soubeyran, A Simple Model of Brain Circulation, June 2005

1485 Carsten Hefeker, Uncertainty, Wage Setting and Decision Making in a Monetary Union, June 2005

1486 Ondřej Schneider and Jan Zápal, Fiscal Policy in New EU Member States - Go East, Prudent Man!, June 2005

1487 Christian Schultz, Virtual Capacity and Competition, June 2005

1488 Yvan Lengwiler and Elmar Wolfstetter, Bid Rigging - An Analysis of Corruption in Auctions, June 2005

1489 Johannes Becker and Clemens Fuest, Does Germany Collect Revenue from Taxing Capital Income?, June 2005 
1490 Axel Dreher and Panu Poutvaara, Student Flows and Migration: An Empirical Analysis, June 2005

1491 Bernd Huber and Marco Runkel, Interregional Redistribution and Budget Institutions under Asymmetric Information, June 2005

1492 Guido Tabellini, Culture and Institutions: Economic Development in the Regions of Europe, July 2005

1493 Kurt R. Brekke and Michael Kuhn, Direct to Consumer Advertising in Pharmaceutical Markets, July 2005

1494 Martín Gonzalez-Eiras and Dirk Niepelt, Sustaining Social Security, July 2005

1495 Alfons J. Weichenrieder, (Why) Do we need Corporate Taxation?, July 2005

1496 Paolo M. Panteghini, S-Based Taxation under Default Risk, July 2005

1497 Panos Hatzipanayotou and Michael S. Michael, Migration, Tied Foreign Aid and the Welfare State, July 2005

1498 Agata Antkiewicz and John Whalley, BRICSAM and the Non-WTO, July 2005

1499 Petr Hedbávný, Ondřej Schneider and Jan Zápal, A Fiscal Rule that has Teeth: A Suggestion for a 'Fiscal Sustainability Council' underpinned by the Financial Markets, July 2005

1500 J. Atsu Amegashie and Marco Runkel, Sabotaging Potential Rivals, July 2005

1501 Heikki Oksanen, Actuarial Neutrality across Generations Applied to Public Pensions under Population Ageing: Effects on Government Finances and National Saving, July 2005

1502 Xenia Matschke, Costly Revenue-Raising and the Case for Favoring Import-Competing Industries, July 2005

1503 Horst Raff and Nicolas Schmitt, Why Parallel Trade may Raise Producers Profits, July 2005

1504 Alberto Bisin and Piero Gottardi, Efficient Competitive Equilibria with Adverse Selection, July 2005

1505 Peter A. Zadrozny, Necessary and Sufficient Restrictions for Existence of a Unique Fourth Moment of a Univariate GARCH(p,q) Process, July 2005

1506 Rainer Niemann and Corinna Treisch, Group Taxation, Asymmetric Taxation and Cross-Border Investment Incentives in Austria, July 2005

1507 Thomas Christiaans, Thomas Eichner and Ruediger Pethig, Optimal Pest Control in Agriculture, July 2005 
1508 Biswa N. Bhattacharyay and Prabir De, Promotion of Trade and Investments between China and India: The Case of Southwest China and East and Northeast India, July 2005

1509 Jean Hindriks and Ben Lockwood, Decentralization and Electoral Accountability: Incentives, Separation, and Voter Welfare, July 2005

1510 Michelle R. Garfinkel, Stergios Skaperdas and Constantinos Syropoulos, Globalization and Domestic Conflict, July 2005

1511 Jesús Crespo-Cuaresma, Balázs Égert and Ronald MacDonald, Non-Linear Exchange Rate Dynamics in Target Zones: A Bumpy Road towards a Honeymoon - Some Evidence from the ERM, ERM2 and Selected New EU Member States, July 2005

1512 David S. Evans and Michael Salinger, Curing Sinus Headaches and Tying Law: An Empirical Analysis of Bundling Decongestants and Pain Relievers, August 2005

1513 Christian Keuschnigg and Martin D. Dietz, A Growth Oriented Dual Income Tax, July 2005

1514 Fahad Khalil, David Martimort and Bruno Parigi, Monitoring a Common Agent: Implications for Financial Contracting, August 2005

1515 Volker Grossmann and Panu Poutvaara, Pareto-Improving Bequest Taxation, August 2005

1516 Lars P. Feld and Emmanuelle Reulier, Strategic Tax Competition in Switzerland: Evidence from a Panel of the Swiss Cantons, August 2005

1517 Kira Boerner and Silke Uebelmesser, Migration and the Welfare State: The Economic Power of the Non-Voter?, August 2005

1518 Gabriela Schütz, Heinrich W. Ursprung and Ludger Wößmann, Education Policy and Equality of Opportunity, August 2005

1519 David S. Evans and Michael A. Salinger, Curing Sinus Headaches and Tying Law: An Empirical Analysis of Bundling Decongestants and Pain Relievers, August 2005 